\section{Otherness, biology and eugenics}

\author{
The Unfit: A History of a Bad Idea \\ By Elof Axel \\ Cold Spring Harbor Laboratory Press, \$39.00, ISBN 0-87969-587-0, 2001
}

\section{Reviewed by John Waller}

The Wellcome Trust Centre for the History of Medicine at University College London, London, UK.

Social essentialism has always been with us, as The Unfit makes abundantly clear. Clusters of individuals sharing an attribute such as color, background or belief are lumped into the same mental category, onto which are projected the qualities most feared or despised by rival groups. Any awareness of the enormous range of appearance, thought and temperament that exists in any human group is thus replaced by a crude, usually ugly, caricature.

Not surprisingly, social essentialism has furnished excusatory captions to many of humanity's most barbaric actions agains the weak and friendless - from the 'bestial' aborigines of Victorian propaganda, to the 'subversive' Jew of Nazi ideology. This kind of dehumanization typically accompanies a withdrawal of compassion. It also allows unspeakable actions to be taken against masses of people without the perpetrators' sense of themselves as moral beings and model citizens ever being seriously troubled.

Carlson's The Unfit: A History of a Bad Idea explores several major episodes in the history of social essentialism. $\mathrm{He}$ begins with Old Testament injunctions to destroy certain peoples for alleged wickedness: early — though by no means the first-attempts to label other ethnic groups as irremediably evil. Carlson then moves directly to the seventeenth century to recount the sorry tale of how doctors, purveying a new biological vision of society, argued that masturbation engendered sickness, insanity and defective children.

The rest of this richly detailed book focuses on the growth of biological definitions of degeneracy during the 1800s and their culmination in the eugenics movements of Europe and the United States during the twentieth century. The notion that aspects of character are rooted in the individual's physiological makeup provided a new and powerful rationale for social dominance. It is in this vein that Carlson traces the origins of the biological theories of race, intelligence and moral turpitude that by the 1890 s had come to obsess scientists, social commentators, novelists and, in some countries, statesmen and lawmakers. The Unfit documents how these concepts of biological unfitness provided an analgesic for the consciences of American and European governments, which, having biologized social problems, then introduced eugenic legislation as a means of obviating them.

A major strength of this book is that it follows the roots of this mindset back to the early decades of the nineteenth century. Thus, unlike most existing accounts, it appropriately begins its narrative well before the idea of selective human breeding became popular. Carlson's treatment of twentieth-century eugenics is necessarily more conventional, as this has been so extensively covered elsewhere. Nevertheless, it is a story that cannot be repeated too often. Perhaps the most laudable goal of historical study is to teach us more about our own potential for inhumanity. Our collective past shows us what we can become when economic interests collide with our moral virtues, and how readily the latter give way to the former in times of hardship — when jobs are scarce, labor is restless and scapegoats are required to assuage our own sense of defeat.

Appropriately, then, Carlson stresses the fact that support for eugenics was never limited to an ignorant and hardhearted right wing. Nor was it confined to propertied classes disturbed by rising crime rates and the tax burden of caring for those unable to carry out economic duties. During the early decades of the twentieth century, the desire to reduce the fecundity of the poorer classes was also a prominent part of the 'progressive's' political platform. And, in both Europe and America, until the post-World War II era, to be a geneticist was, in most cases, to be an advocate of selective human breeding as well. That several of these geneticists were committed apologists of the Soviet regime makes clear that this was an outlook that pervaded almost the entire political spectrum.

Carlson also reminds us that practical eugenics was not an exclusively German phenomenon. By the 1930s, thirty American states had introduced involuntary sterilization programs that eventually resulted in the sterilization of over 60,000 mentally and physically ill persons. In Scandinavia, a series of reformist governments were no less enthusiastic about preventing parentage among the 'unfit'. Between 1934 and 1960, 30,000 mentally ill individuals were sterilized in Sweden alone.

That the eugenic temptation is a strong one, and that no political persuasion has been immune to its supposed charms, is something of which we need to be acutely aware. The chief value of The Unfit lies in its providing an introduction to this critical issue that is accessible to both the student and to the general reader. A final chapter dealing with modern genetics, and the ethical dilemmas we now face, rightly emphasizes the relevance of the past to the present.

This book does have a few weaknesses, however, that ought to be mentioned. Carlson is a little too ready to sanitize the involvement of biologists in the eugenics movements of the 1920s and 1930s. For instance, he gives the distinct impression that only second-rate scientists, such as Charles Davenport, favored mass sterilization programs (negative eugenics). Certainly, leading geneticists like Hermann Müller spoke of promoting the birth of more intelligent children rather than sterilizing the poor, criminal or insane (positive eugenics). But this distinction must not be overdrawn. Plenty of bona fide scientists also favored repressive legislation. For instance, R.A. Fisher, the renowned mathematical population geneticist, strongly supported measures to curb the reproduction of those deemed genetically unfit.

Carlson also exaggerates the damage done to the eugenics movements of Europe and America by the crimes of the Nazi regime. As the historian Diane Paul has shown, post-War pioneers of genetic screening often couched their roles in terms of protecting society from the offspring of those carrying 'undesirable' traits. Similarly, having first denounced the Nazi model as a corruption of a potentially sound idea, many scientists (James Neel and Hermann Müller among them) continued to advocate methods of improving the genetic quality of mankind. It was not until the 1960s that talk of hereditary intelligence, criminality, racial differences and eugenics fell into disrepute.

Despite these flaws, The Unfit neatly complements, if it does not supplant, the existing literature in this field. Informative and generally reliable, it deals with a tremendously important issue in a sensitive and responsible manner. It can only be hoped that books like this one will help lessen our susceptibility to essentialistic thinking. 